University of Wollongong

Research Online

Faculty of Social Sciences - Papers (Archive) Faculty of Arts, Social Sciences \& Humanities

2014

Structural equation modelling to assess relationships between eventrelated potential components, heart rate and skin conductance in the context of emotional stimuli

Susan Thomas

University of Wollongong, sthomas@uow.edu.au

Peter Leeson

University of Wollongong, pleeson@uow.edu.au

Craig Gonsalvez

Universty of Western Sydney

Stuart Johnstone

University of Wollongong, sjohnsto@uow.edu.au

Follow this and additional works at: https://ro.uow.edu.au/sspapers

Part of the Education Commons, and the Social and Behavioral Sciences Commons

Research Online is the open access institutional repository for the University of Wollongong. For further information contact the UOW Library: research-pubs@uow.edu.au 


\title{
Structural equation modelling to assess relationships between event-related potential components, heart rate and skin conductance in the context of emotional stimuli
}

\author{
Abstract \\ Abstract of a poster presented at the 17th World Congress of Psychophysiology (IOP2014) of the \\ International Organization of Psychophysiology (IOP) Hiroshima, Japan, September 23rd to 27th, 2014. \\ Keywords \\ emotional, stimuli, modelling, assess, relationships, between, event, related, potential, structural, \\ components, equation, heart, rate, skin, conductance, context \\ Disciplines \\ Education | Social and Behavioral Sciences \\ Publication Details \\ Thomas, S. J., Leeson, P. R. C., Gonsalvev, C. J. \& Johnstone, S. J. (2014). Structural equation modelling to \\ assess relationships between event-related potential components, heart rate and skin conductance in the \\ context of emotional stimuli. International Journal of Psychophysiology, 94 (2), 245-246.
}

This journal article is available at Research Online: https://ro.uow.edu.au/sspapers/1282 


\title{
Structural equation modelling to assess relationships between event-related potential components, heart rate and skin conductance in the context of emotional stimuli
}

\author{
Susan J. Thomas ${ }_{a}$, Peter R.C. Leeson ${ }_{b}$, Craig J. Gonsalvez ${ }_{c}$, Stuart J. Johnstone ${ }_{d}$
}

${ }_{a}$ Graduate School of Medicine and Brain \& Behaviour Research Institute, University of Wollongong, Australia

${ }_{b}$ School of Psychology, University of Wollongong, Australia

SSchool of Social Sciences and Psychology, University of Western Sydney, Australia

${ }_{d}$ Centre for Psychophysics and Psychopharmacology, and School of Psychology, University of

Wollongong, Australia

Background: Emotions are associated with central (CNS) and autonomic (ANS) nervous system arousal, which can be indexed through psychophysiological changes in event-related potentials (ERPs), heart rate and skin conductance to emotional compared to neutral stimuli. Relationships between these variables are complex and inadequately understood. ERP changes to emotional stimuli, for example, may reflect the activity of cortical regulation of limbic emotional areas or, conversely, increased attention to emotionally salient stimuli. The current study aimed to provide a stronger assessment of the relationship among these variables than is provided by analysing multiple levels of data separately or using traditional correlational approaches.

Method: We employed structural equation modelling to assess pathways between eventrelated potential component amplitudes and latencies, heart rate and skin conductance, and to statistically assess their relationship to a latent variable of emotional arousal. Twenty healthy volunteers responded to 500 trials of randomly mixed threat and neutral words with simple task requirements performed using a button press device. The psychophysiological data (ERP component amplitudes and latencies, heart rate and skin conductance) to threat and neutral stimuli were included in the analysis. An initial correlational analysis was performed, followed by structural equation modelling using AMOS software (Version 19) in order to clarify interactions among the variables. Fit indices for uni and multi-dimensional models of emotional arousal were compared.

Results: We present a schematic of the best-fitting parsimonious model to account for pathways between the variables. The model outlines both relationships and fractionation between these ANS and CNS psychophysiological measures and the hypothesised underlying concept of emotional arousal.

Discussion: The results suggest that the structural equation modelling and latent variable analysis is a useful approach to better understanding complex relationships amongst these different levels of CNS and ANS psychophysiological measurement.

Conclusion: Structural equation modelling helped to clarify relationships between multiple psychophysiological measures of ANS and CNS arousal in the current study. Structural equation modelling may be underutilised in the field of psychophysiology to date. 